Research Article

\title{
Determinants of Secondary School Teachers' Job Satisfaction in Tanzania
}

\author{
Gilman Jackson Nyamubi \\ Department of Education, University of Iringa, P.O. Box 200, Iringa, Tanzania \\ Correspondence should be addressed to Gilman Jackson Nyamubi; gilmubi@yahoo.com
}

Received 10 June 2016; Revised 22 October 2016; Accepted 15 January 2017; Published 1 February 2017

Academic Editor: Peter Howley

Copyright ( 2017 Gilman Jackson Nyamubi. This is an open access article distributed under the Creative Commons Attribution License, which permits unrestricted use, distribution, and reproduction in any medium, provided the original work is properly cited.

\begin{abstract}
This study examined teachers' job satisfaction in Tanzania. It addressed one research question: what factors determine secondary school teachers' job satisfaction? The study was conducted in eight secondary schools in two regions of Tanzania. It used focus group discussion as the data collection tool. Results show that teachers were satisfied by both monetary and nonmonetary incentives such as community support. They were pleased with fair remuneration packages that related to their labour input, opportunities for career development, a well-defined individual appraisal system, timely promotion, and requisite workplace conditions. The study also showed that teachers' friendship and cooperation with coworkers and students as well as the respect of community members also enhanced their satisfaction in teaching. Also important to their satisfaction is their students' success in and after school, which reveals the teachers' sense of duty and responsibility. Teachers' job dissatisfaction can lead to their search for other means to gain economically. It is recommended that care should be given to address teachers' pertinent issues, especially salaries, workplace conditions, and timely promotion, to enhance teachers' physical and mental attachment to their workplaces.
\end{abstract}

\section{Introduction}

Provision of quality education is important for facilitating a nation's development. Research has found that, to improve individual learners' values, attitudes, behaviours, and skills, quality education is of paramount importance [1-3]. Teachers are the heart of classroom instruction, so they are key to learners' productivity and hence to society's efficiency. Teachers' effectiveness depends on their competence, both academic and pedagogical, as well as a correlation between their training and skills and their position, workload, and work encouragement [2]. Their satisfaction with their jobs is the focus of this study. While there are many studies on workers' job satisfaction, little has been investigated about teachers' job satisfaction, particularly among secondary school teachers in Tanzania. To gain this insight, the article attempts to answer one important question: what factors determine secondary school teachers' job satisfaction?

Accepting the teaching role calls for sacrifice and devotion. Alongside the demands of teaching, teachers have other duties such as guiding, counselling, and disciplining students and managing classes [4]. For teachers to devote their efforts to serving the community, they need to see that they are valued and are being properly supplied with the things necessary for them to accomplish their duties.

When teachers are at school, they require a conducive workplace environment to conduct their profession effectively. They also need adequate remuneration [5]. According to Narimawati [6], employees are attracted to jobs that make it possible for them to meet their daily needs. Unless these needs are achieved, teachers cannot realise their full potential and will begin to be less committed to teaching. Rasku and Kinnunen [7] found that Finnish secondary school teachers expressed satisfaction in teaching when they were assured of their well-being both economically and in the workplace environment.

With regard to income, teachers' appreciation of their schools is enhanced by the salaries they receive, especially when these salaries correspond to their levels of education, responsibilities they hold, and duties they perform in the school [4]. For teachers, financial rewards are an important aspect in relation to their satisfaction in teaching and related services. Arguably, when teachers feel positive about 
their income, especially their salaries, their accountability is boosted.

It is believed that, to generate teachers' commitment to the school, overall job satisfaction and perceptions of school support are key emotional and cognitive attributes. Teachers' feelings of job satisfaction operate through independent channels to mediate the impact of work experiences on their devotion to the school [8]. Sometimes job satisfaction is affected by whether the outside world is perceived as supportive or not. In Kenya, it is reported that, more than ever before, teachers do not feel supported. Instead, they experience tremendous and constant pressure from politicians, parents, and local communities to deliver quality education [4]. Overwhelming pressure to perform in the absence of support might explain secondary school teachers' dissatisfaction with their work.

\section{Methodology}

This qualitative study was designed to explore determinants of job satisfaction among secondary school teachers in Tanzania, using an in-depth exploration of teachers' perceived contentment. The research provided respondents with an opportunity to express their feelings and views about job satisfaction.

2.1. Study Sites and Participants. The study was conducted in Kilimanjaro and Lindi Regions of Tanzania. These regions were purposely selected on the basis of their performance in the 2015 national examinations. Kilimanjaro was in the higher performing cluster while Lindi was in the lower. In addition, the two regions have different historical relations to education provision in Tanzania. The Kilimanjaro Region had an early contact with European missionaries and so accessed modern education ahead of other regions [9]. Lindi had no such contact and consequently remains one of the regions that lag behind in terms of access to secondary education.

In each region, four secondary schools were purposely selected for the study. Schools were chosen based on three criteria: location (urban or rural), performance in national examination (high or low), and type of school ownership (private or public). For government secondary schools, both old-established and new community schools were chosen. For private schools, the selection of participating schools depended on a variety of ownership categories. Four categories of private school ownership exist: Christian schools, Muslim schools, schools operated by the Tanzania Parents' Association, and schools that are owned by Trust Funds and Cooperatives. In all, one school from each category was selected.

The wide-ranging types of school ownership allowed the researcher to discover varying teachers' views, reflections, and opinions as they related to the teaching environments. Secondary school teachers in Tanzania are paid differently depending on the income and economic power of their employers. Thus, in each region, two public secondary schools and two private ones in both rural and urban settings were selected, based on the mentioned criteria.
Focus group discussion was the main data collection tool. Groups of between eight and twelve teachers with similar backgrounds were invited to participate in these groups. The advantage of focus groups is that participants could interact with each other rather than with just the researcher. The interaction created an opportunity for participants to engage in a conversation regarding the topic of investigation. This ensured confirmability of data. The role of the researcher was to guide the proceedings of the discussion. Semistructured questions were prepared beforehand to guide the discussion.

2.2. Data Management and Analysis. Focus group discussions were recorded using a tape recorder. They were transcribed verbatim, and transcripts in Kiswahili were translated into English and printed. Data were analysed following a thematic analysis framework, using the NVivo version 7.0 computer software for analysing qualitative data. Codes were assigned to a section of transcribed data where a word or phrase was taken. This facilitated putting together concepts or themes that were raised by respondents thus helping in developing data categories. Care was taken to ensure that only terms that occurred throughout the whole data set were taken to constitute major categories that were later developed into themes. Participants' quotes were selected to illustrate the themes and topics that emerged for discussion.

\section{Findings and Discussion}

Data on job satisfaction emerging from the inquiry showed factors that were clustered into three categories: first, monetary incentives; second, satisfaction with the school and the work environment created for the teachers; third, satisfaction with society.

3.1. Monetary Incentives. With regard to monetary incentives, most respondents desired their income to correspond to their workload. Thus, such aspects as monthly salaries, transfer allowances, periodic adjustments to their salary scales, and leave allowances had to be realistic. This is in line with Jonathan et al. [5] who found that teachers' job satisfaction would be improved if their welfare and workplace conditions such as streamlining salary structures and remuneration packages are fine-tuned in proportion with other professions.

The reason why monetary incentives matter is that they are a tangible expression of the school and community's value of the teacher. The relationship between teachers' labour and the kind of remuneration they were given translates to commendation for work and recognition of their value. As argued by Albee and Piveral [10], appropriate salary levels foster commitment, thereby assuring that capable individuals continue to work in the school.

It was found that teachers are satisfied by both good salaries and flexible teaching schedules. Better incomes and benefits are instrumental in satisfying teachers' economic needs. Salami [11] similarly found that professionals who are typically well paid benefit their organisation throughout their career span. Good salary is also necessary to recruit wellqualified teachers. 
Issues of inequitable salary scales for teachers with the same qualifications and work experience in the same schools were raised by several respondents in several private secondary schools. Teachers were particularly concerned about such irregularities. Most respondents raised the issue of delayed salaries. One of them had this to say:

We are given different salary scales although
having the same qualifications and teaching expe-
rience. The salary is unreliable. Sometimes, I go
without pay for a period of 3 to 4 months. This
is painful. I have adopted survival strategies such
as giving private tuition. (Teacher, School E, Lindi
Region)

The findings from this study showed that teachers in secondary schools expressed dissatisfaction with their salary levels, fringe benefits, and allowances. Therefore, they felt the need to top up their salaries with nonteaching activities such as private tutoring, small-scale businesses, gardening, and animal keeping. As a result, teachers were much less committed to their primary jobs.

Nguni [12] found that the majority of teachers complained about poor salaries, which explains why they embarked on second jobs, mostly to the detriment of their school and students. The same study revealed, as is also the case in the present study, that a lot of teachers searched for alternative teaching opportunities or changed jobs to increase their income. Teachers' salaries were insufficient to support their families to live decently.

Voices were raised concerning unrealistically low remuneration packages. In addition, delays in receiving their monthly salary hampered teachers' devotion to perform their duties because they found life hard, which affected their intention to remain with their employer. The findings indicated that teachers working in government schools are not paid the same level as other Tanzanian civil servants despite similarities in academic qualifications. One teacher, for example, pointed out the following:

\section{I am in the teaching profession, but my colleagues who joined other institutions such as the Tanzania Revenue Authority are well paid. We are all university graduates, but the salary scales are different. When I think of this by looking at how I am doing at school, I get discouraged. (Teacher, School A, Kilimanjaro Region)}

Attractive remuneration packages enhanced teachers' attachment to the school. Yet government secondary school teachers had fixed salary scales determined centrally by the government. Nguni [12] observed that top administration in schools does not determine teachers' salaries because they are centrally determined by the government, irrespective of the amount of teachers' actual work or the quality of that work.

According to some teachers, the government recognises the insufficiency in salaries and encourages teachers to commit themselves to the school but also denies them the opportunity to seek extracurricular sources of income. The following is one of the comments made by teachers:

\begin{abstract}
In a government school, I feel satisfied because I get enough time to do my personal activities. I have economic activities to attend to, particularly my farm, garden and poultry project. I earn enough money to support my family. The only time I am at school fully is when I teach or when I am on duty. (Teacher, School C, Kilimanjaro Region)
\end{abstract}

Salary scales in private secondary schools, in contrast, were determined largely by specific schools' income and negotiations between employers and teachers. School heads or school managers often create packages that are employeefocused. Thus, what teachers obtain differs from one private secondary school to another.

With regard to equitable rewards in the form of pay, several teachers expressed satisfaction and increased devotion to their duties when they perceived such rewards as fair. It is argued along the same line as Liu and Wang's [13] study that employees are satisfied when they perceive that fair decisions are made resulting from policies and procedures which fix salary scales that correspond to their tasks. Thus, it is only when these basic conditions are met, irrespective of whether the school is public or private, that both teachers and employers are satisfied. Teachers quitting or working additional jobs and shirking their binding responsibilities are the dangerous consequences of not providing adequate teacher salaries.

As experience from other countries shows, employees who are deprived of deserved salary and rewards experience job dissatisfaction $[4,7,14]$. Hence, either teachers strive to seek other means of economic gain or they leave to seek work elsewhere.

Diminishing devotion to their duties because of poor remuneration was profoundly true of teachers in government secondary schools, although it was also the case for a few teachers in the sampled private secondary schools. In both cases, teachers experienced unequal treatment in terms of their salary, compared to employees in other public or private sector institutions, despite similarities in the academic or professional qualifications. These findings are similar to those proposed by Michael [15] describing private firms. Private firms use calculative, instrumental, and business-oriented approaches in paying employees. They make greater use of performance-based pay, individual appraisal systems, and direct communication with employees, leading to salary negotiations that result in employees' attachment to their places of work.

3.2. Satisfaction with the School. With regard to the contribution of the school to teachers' job satisfaction, findings revealed that several factors beyond mere remuneration led to teachers' well-being. Most teachers said that timely and regular promotion would contribute to their comfort with the profession, but they reported that often their deserved or expected promotions were not realised. The teachers stated that lack of timely promotion hindered their readiness to serve their employer. One teacher, for example, pointed out the following: 
We are not promptly promoted. Teachers have no problem with working hard, but when our basic rights are compromised, we become dissatisfied. Personally, I am committed to teaching, but when I see that my promotion is delayed, and I am not getting salary increments, I feel disappointed. (Teacher, School F, Lindi Region)

Sharma and Bajpai [16] observe that employees' satisfaction with promotional opportunities depends on several factors, including the probability that employees perceive fairness in the encouragement process in terms of the timing of promotion after meeting the required standards. In the present study, quite a lot of participants reported dissatisfaction resulting from delayed promotion and subsequent failure to increase their salary increment.

Overall, teachers displayed happiness with the profession when they were provided with an opportunity for academic and professional development as well as timely promotion. This enhanced their advancement in the realm of skills, capacity, and experience. Teachers' loss of morale, especially in government secondary schools, had roots in their loss of hope that the government would address their concerns regarding salary scales and timely promotion. Such results align with findings on a study regarding predictors of job satisfaction among Nigerian teachers by Ololube [8]. Results revealed that employees who perceive limited opportunities for career advancement and low salary have decreased job satisfaction.

The issue of teaching and learning materials was of paramount importance for sustaining teachers' eagerness to work. The majority of teachers pointed out that they were frustrated when they had not received the teaching materials needed to help students understand concepts being taught. They mentioned that the nonavailability of teaching materials was an obstacle to their optimal output. This demoralised them because they were unable to serve students effectively. The following was mentioned by one teacher:

I teach chemistry, but, at the school, there is no laboratory equipment. How can I rely on abstract content teaching? Science needs learning by doing. Students need to see and learn the subject matter practically. (Teacher, School E, Lindi Region)

Another respondent reported the following:

Our school lacks laboratories for all science subjects. Do you expect students to get divisions one and two in national examinations? It is difficult. Students' failure makes me demoralised because the society considers that I am unable to perform and do my work better. (Teacher, School D, Kilimanjaro Region)

Teachers attributed their inability to meet society's expectations of students' performance to the absence of requisite teaching and learning materials. In a study conducted about job satisfaction among secondary school teachers in Transkei, South Africa, Mwamwenda [17] revealed that teachers were also concerned about the inadequate supply of teaching and learning materials.

In addition, government or community's failure to meet basic infrastructure standards when a school was established put a strain on teachers. One teacher complained as follows:

There are many problems in these newly established community secondary schools. The proper requirements were lacking when the schools were started. This puts a burden on us teachers. (Teacher, School F, Lindi Region)

Teachers' positive feelings about workplace conditions enhanced their work in a way that promoted their attachment to the job. As argued by Odhiambo [18], productivity at the workplace is optimised when workers perceive sufficient attention being given to their physical work facilities. Teachers asserted that their teaching life was difficult when workplace conditions lacked basic teaching facilities and resources.

Nearly all respondents were discontented about deteriorating work conditions, especially in most public secondary schools. One teacher, for example, said the following:

The government does not focus on how students learn and whether or not there are good classrooms, libraries, laboratories or learning and teaching materials. It just encourages people in the community to erect sub-standard buildings they call classrooms, but with no teachers or requisite work conditions. How can students acquire knowledge and skills under such conditions? (Teacher, School G, Lindi Region)

The teachers indicated that if education providers (both government and private school managers) did not carefully address the issue of undesirable workplace conditions, their schools would remain buildings with no teachers. At best, teachers would be at their workplace physically, but their commitment would be elsewhere.

Workplace conditions surfaced as a factor that accounted for teachers' satisfaction with their teaching and attachment to their school in a number of ways. Teachers responded differently regarding an issue of workplace conditions, depending on the physical space and facilities that their schools provided. Some government and private schools had averageto-good facilities such as teachers' houses, while others lacked the same. It was observed in one private school, for example, that each teacher had a specific place in which to carry out his or her duties comfortably. The staffroom had a notice board, chairs, and tables for every teacher as well as a computer connected to the Internet.

In general, however, in most government secondary schools, teachers lacked adequate office space necessary for reading, lesson preparation, or marking of students' assignments and exercises. Teachers often had to share office space and furniture, and, ultimately, this affected their concentration and productivity.

These findings imply that the need to address workplace conditions is an issue of paramount importance if teachers 
are to have their total physical and mental presence at their workplace. Employers' failure to meet teachers' basic requirements put strain on teachers, resulting in reduced morale.

Regarding teachers' opportunities for professional development, some respondents reported that, through the support and encouragement of schools heads, teachers went for further studies in higher learning institutions. Professional growth allowed advancement or increased responsibility. The following was reported:

We are given part of the fees and a per diem when we travel for science laboratory work and examinations, and we use the school library for our studies. This scheme promotes our devotion to our school's advancement. (Teacher, School D, Kilimanjaro Region)

Teachers' opportunities for career advancement exerted an influence on their job satisfaction, comfort in the profession, and readiness to serve their employers. Teachers' satisfaction with the day-to-day execution of their duties was achieved when they believed that their future prospects were good. This finding matches experiences in Israel [19] that teachers' professional development and growth in their current workplace enhances their satisfaction and encourages persistence in teaching.

Support for teachers was also reflected in the way the school administration provided opportunities for them to perform school duties with minimal supervision. There is empirical evidence from various studies that teachers' good relations with their supervisors and coworkers affect job satisfaction $[4,20,21]$. These researchers agree that job satisfaction is related to employees' opportunities to interact with others at the workplace. Wasserman and Yehoshua [19] emphasize that lowering of supervisory pressure on teachers improves their teaching and strengthens the cooperation of the teachers with the administration and their work colleagues.

Teachers were happy to work hard because of the satisfaction they obtained from the friendships they had established with coworkers, students, and parents. The respect they received from community members, the moral satisfaction of their profession, and the pleasure they acquired by seeing their students excelling after school sustained their morale at work.

Some teachers reported that they had gained significantly by making friends with their leaders, fellow staff members, and students, whose affection was of help in time of need. Care and support from significant others reinforced teachers' attachment to the school and the teaching profession. One teacher reported the following:

I was once seriously sick. I am single. I do not live with any family member. Fellow teachers and my students helped me. They took care of me. I am glad to have friends. (Teacher, School B, Kilimanjaro Region)

These results support the findings of previous studies, such as that by Sirima and Poipoi [4] who analysed perceived factors influencing public secondary school teachers' job satisfaction in Kenya. In their study, findings revealed that the greatest need for teachers centres on interpersonal needs. Healthy relationships with colleagues and school leaders significantly increase teachers' concern for delivering good educational services. The results from a study conducted in Tanzania by Jonathan et al. [5] reflect similar observations that the quality of close friendships among employees promotes positive work outcomes. Additionally, friendship opportunities are associated with increased job satisfaction, job involvement, and commitment to the school. Thus, a school should seek to create group cohesion amongst its teachers.

3.3. Satisfaction with Society. Most teachers reported that they were generally satisfied with the recognition they received from the surrounding community. One teacher, for example, said the following:

Community members accord me respect. I am teaching their children. This impresses me, and I am happy that my contribution is recognised. (Teacher, School A, Kilimanjaro Region).

Teachers express satisfaction with teaching when they perceive that community members recognise and respect their contribution to education. Teachers work hard at helping students learn because they expect to receive respect for the role they play in addressing students' physical, academic, and moral growth [22], which is for the betterment of individual students, their parents, and the nation as a whole.

The nature of societal orientation in Tanzania influences community members' readiness to support the schools' management practices within specific community settings [15]. In other words, the preliberalisation society in Tanzania lived according to a socialistic ideology, which promoted cooperation in building the nation. Teachers were regarded as primary participants in maintaining social cohesion in society, which made the teaching profession satisfying to them.

On the other hand, the absence of community support in recent times has resulted in teachers' decreased morale in their work. Quite a lot of teachers attributed lack of support to the change in the perceived purpose of education in liberalised Tanzania. It was observed that the provision of education in a liberalised economy focused on values that stressed individual rather than communal gains from education [15]. A corollary to this is parents' belief that teachers are conducting their profession for individual reasons (such as salary, rewards, or other incentives), rather than because they are dedicated to teaching.

In response to the idea that money can potentially impel them, most teachers reported that in fact they were pleased to be teachers. According to them, teaching gave them the moral and social benefits inherent in the profession, most notably being free from corrupt practices. This result is consistent with the findings regarding caring teaching as a moral practice by Gholami and Tirri [22]. It was found that teaching is a practice that gives teachers pleasure when they 
bring about students' learning. This was substantiated by the field findings:

\section{What makes me satisfied with the teaching career is that, despite everything, I am performing my duties without being prone to corruption, meaning that there is no room for corruption practices as is the case in other professions! I use my energy to get what makes me live a happy life. (Teacher, School $D$, Kilimanjaro Region)}

Most teachers acknowledged that while good salary is a concern, they also need moral satisfaction and the appreciation of community members. They reported that a teacher could survive lower wages if he or she is appreciated for his or her performance. Most respondents reported that they were gratified when they saw their former students excel in life after school. One had this to say:

\section{I am satisfied when I see my students excel. When I come across my former students, I am satisfied that I had not only taught that person the subject matter, but I also helped to equip a person who is helping the nation. (Teacher, School E, Lindi Region)}

Supporting this assertion, another respondent remarked the following:

Teachers are satisfied when they see their learners excel in the field of their choice. We have the duty of preparing young ones to be good citizens of the country and excel both academically and socially. Thus, if this is achieved, it makes teachers happy. (Teacher, School C, Kilimanjaro Region)

The teachers' sense of satisfaction that is derived from students' success after school was rooted in their sense of duty, to transform students into responsible citizens. Congruent to this, Gholami and Tirri [22] found that teachers feel a responsibility to be a force for broadening students' intellectual and moral horizons, because it is their role to improve students' moral life focusing on matters pertaining to what is fair, right, just, and virtuous.

The majority of teachers were gratified that they had helped students grow and realise their goals, not only in examinations, but also in relation to moral, ethical, and religious upbringing. These respondents argued that a teacher is primarily called upon to perform his or her duties, and the issue of earning their daily bread was regarded as secondary. According to respondents, a primary motivation was the teachers' inner urge to help students to excel in their future.

\section{Conclusions and Recommendations}

Evidence from the study shows that job satisfaction among secondary school teachers in Tanzania is determined by their positive relationships with coworkers, students, and parents, plus respect and recognition of teachers' contribution in educating society. They were gratified to see their students excel in studies.
Workplace conditions are currently demoralising in many schools. There is vast room for improving teachers' lives and their teaching environment. Unavailability of teaching materials and the absence of laboratory equipment were frustrating. Job dissatisfaction led to teachers' search for alternative tuition or performing nonteaching activities for economic gain. School administrators should do what they can to create a motivating environment.

It is recommended that schools, both public and private, should, first, ensure competitive salaries to retain teachers in their profession; second, employers should address teachers' timely promotion and career advancement to sustain teachers' satisfaction; third, workplace conditions should be enhanced. This will promote teachers' commitment to teaching and their physical presence in the classroom as well as dedication to their students.

This study was limited with regard to its thematic analysis. Usually, it is advised that more than one person should read the transcript and, together, decide the emerging themes [23]. The data were analysed using the NVivo computer programme to come up with themes. However, this does not affect the conclusions of the study, because care was taken to link the eight focus group transcripts through codes to the whole data set from which major categories and themes were developed.

\section{Competing Interests}

The author declares that there are no competing interests regarding the publication of this paper.

\section{References}

[1] K. A. K. Mkumbo, “Teachers commitment to, and experiences of, the teaching profession in Tanzania: findings of focus group research," International Education Studies, vol. 5, no. 3, pp. 222227, 2012.

[2] W. L. Komba, “Teacher professional development in Tanzania: perceptions and practices," Papers in Education and Development, vol. 27, pp. 1-27, 2007.

[3] P. Kavenuke, "What is it that keeps good teachers in the teaching profession? A reflection on teacher retention," Academic Research International, vol. 4, no. 1, pp. 165-174, 2013.

[4] L. C. Sirima and M. W. Poipoi, "Perceived factors influencing public secondary school teachers' job satisfaction in Busia district, Kenya," International Research Journal, vol. 11, no. 1, pp. 659-665, 2010.

[5] H. Jonathan, C. Darroux, and M. Thibeti, "Exploring the effect of job satisfaction and demographic factors on affective, normative and continuance commitment: an empirical evidence of public secondary school teachers in Tanzania," Journal of Education and Practice, vol. 4, no. 23, pp. 85-96, 2013.

[6] S. E. Narimawati, "The influence of work satisfaction, organisational commitment and turnover intention towards the performance of lecturers at west Java's private higher education institution," Journal of Applied Science Research, vol. 3, no. 7, pp. 549-557, 2007.

[7] A. Rasku and U. Kinnunen, "Job conditions and wellness among finnish upper secondary school teachers," Psychology and Health, vol. 18, no. 4, pp. 441-456, 2003. 
[8] N. P. Ololube, "Professionalism, demographics, and motivation: predictors of job satisfaction among Nigerian teachers," International Journal of Educational Policy and Leadership, vol. 2, no. 7, pp. 1-11, 2007.

[9] Z. E. Lawuo, Education and change in rural community: a study of colonial education and local response among Chagga of Kilimanjaro between 1920 and 1945 [Ph.D. thesis], University of Dar es Salaam, Dar es Salaam, Tanzania, 1978.

[10] J. J. Albee and J. A. Piveral, "Management process for defining and monitoring teacher dispositions," International Journal of Educational Management, vol. 17, no. 7, pp. 346-356, 2003.

[11] S. O. Salami, "Demographic and psychological factors predicting organizational commitment among industrial workers," Anthropologist, vol. 10, no. 1, pp. 31-38, 2008.

[12] S. C. Nguni, Transformational Leadership in Tanzanian Education: A Study of the Effects of Transformational Leadership on Teachers' Job Satisfaction, Organisational Commitment and Organisational Citizenship Behaviour in Tanzanian Primary and Secondary Schools, Radboud, Nijmegen, the Netherlands, 2005.

[13] Y. Liu and G. Wang, "Inpatient satisfaction with nursing care and factors influencing satisfaction in a teaching hospital in China," Journal of Nursing Care Quality, vol. 22, no. 3, pp. 266271, 2007.

[14] L.-H. Chen, "Job satisfaction among information system (IS) personnel," Computers in Human Behavior, vol. 24, no. 1, pp. 105-118, 2008.

[15] F. K. Michael, Human resources management practices and employee job satisfaction in private work organisations: a Tanzanian context [Ph.D. thesis], University of Dar es Salaam, Dar es Salaam, Tanzania, 2009.

[16] J. P. Sharma and N. Bajpai, "Organisational commitment and its impact on job satisfaction of employees: a comparative study in public and private sector in India," International Bulletin of Business Administration, vol. 13, no. 2, pp. 97-118, 2010.

[17] T. S. Mwamwenda, "Job satisfaction among secondary school teachers in Transkei," South African Journal of Education, vol. 15, pp. 84-87, 1995.

[18] T. J. Odhiambo, Job satisfaction among graduate teachers in secondary schools in Dar es Salaam region [M.S. thesis], University of Dar es Salaam, Dar es Salaam, Tanzania, 2003.

[19] B. Wasserman and G. Yehoshua, "Relationship between the principal's leadership style and teacher motivation," International Journal of Learning, Teaching and Educational Research, vol. 15, no. 10, pp. 180-192, 2016.

[20] M. Zembylas and E. Papanastasiou, "Sources of teacher job satisfaction and dissatisfaction in Cyprus," Compare, vol. 36, no. 2, pp. 229-247, 2006.

[21] K. Falkenburg and B. Schyns, "Work satisfaction, organizational commitment and withdrawal behaviours," Management Research News, vol. 30, no. 10, pp. 708-723, 2007.

[22] K. Gholami and K. Tirri, "Caring teaching as a moral practice: an exploratory study on perceived dimensions of caring teaching," Education Research International, vol. 2012, Article ID 954274, 8 pages, 2012.

[23] S. K. Shah and K. G. Corley, "Building better theory by bridging the quantitative-qualitative divide," Journal of Management Studies, vol. 43, no. 8, pp. 1821-1835, 2006. 


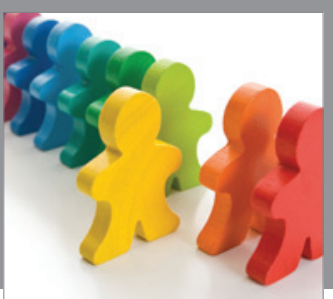

Autism

Research and Treatment
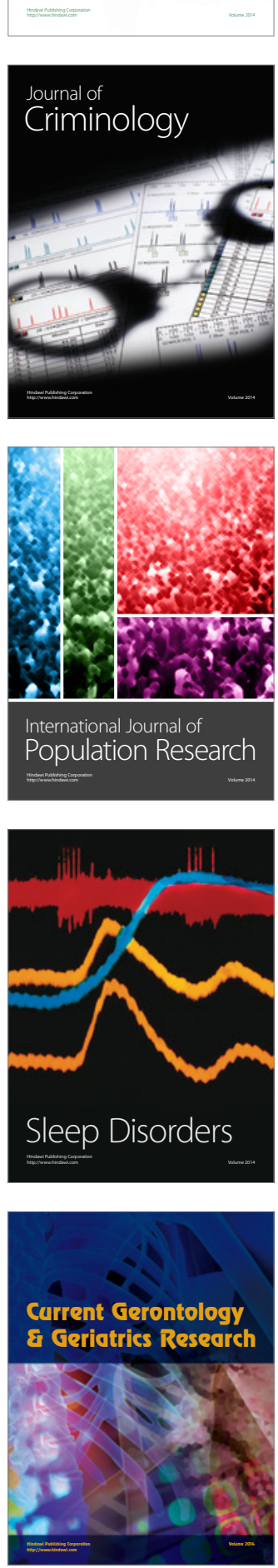

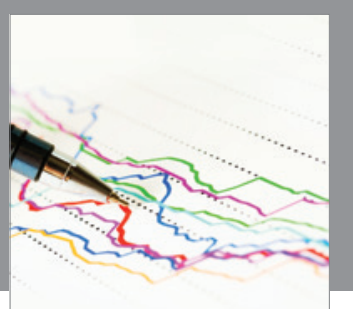

Economics

Research International
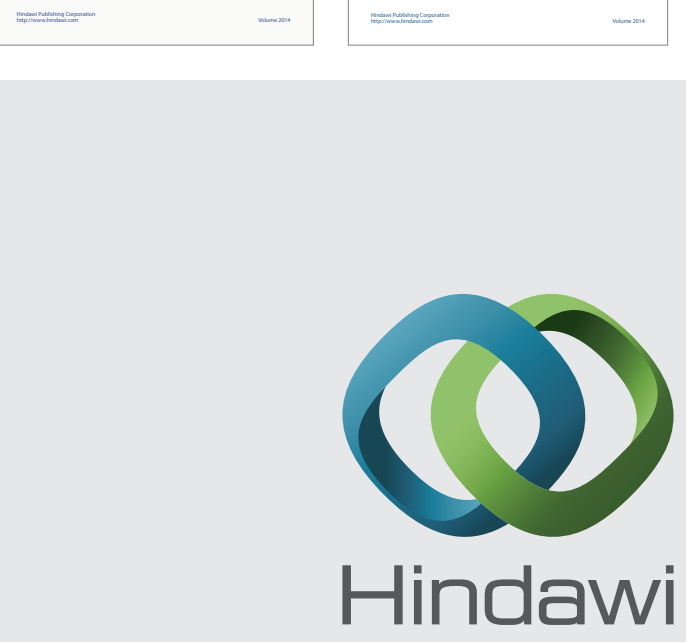

Submit your manuscripts at

https://www.hindawi.com
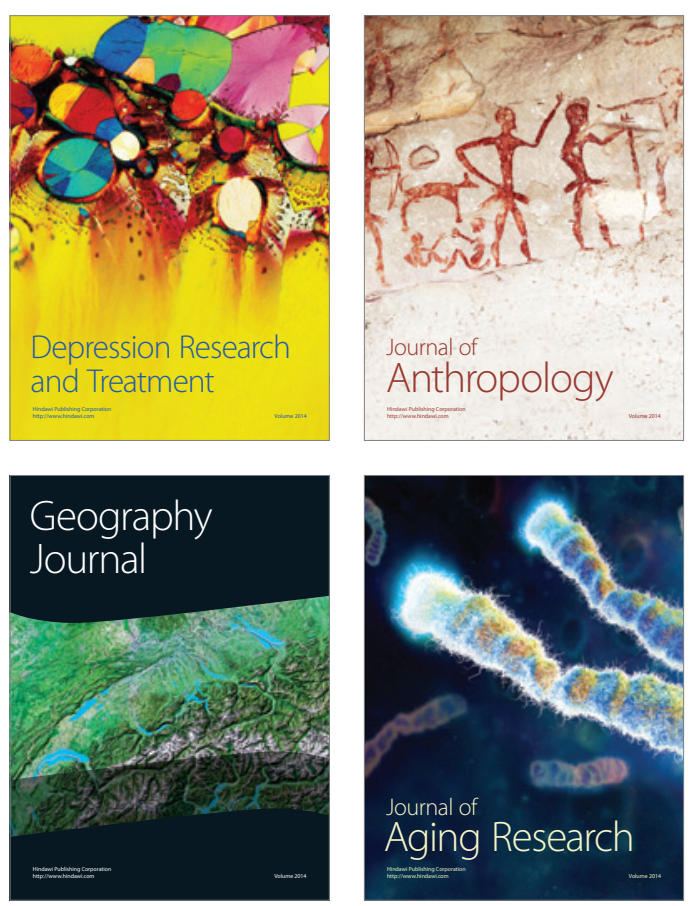
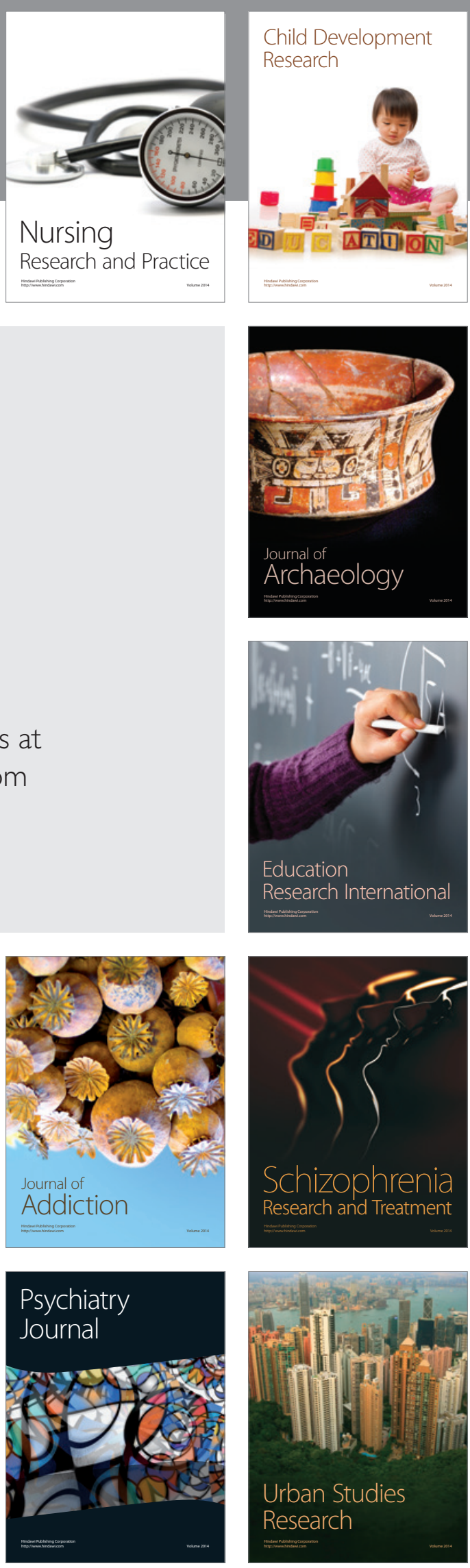